\title{
Relationship between Leadership Behaviors and Nurse Educators' Job Satisfaction
}

\author{
Abeer Mohamed Abd Elkader, Lecturer \\ Nursing Education, Faculty of Nursing, El-Minia University \\ Sanaa Mohamed Aref, Assistant Professor \\ Nursing Education, Faculty of Nursing, El-Minia University
}

\begin{abstract}
Background: Leadership and job satisfaction are recognized as fundamental components influencing the overall effectiveness of an organization. Nursing leaders seldom receive the proper leadership training necessary to lead an academic organization. As a result, the leader may burn out and his/her dissatisfaction may increase. Objective: this study aimed to examine the relationship between leadership behaviors and nurse educators' job satisfaction. Setting: The study was carried out at Faculty of Nursing at Minia University. Subjects: The study sample included a total number of 80 nursing educators. Tools: Two scales were used to collect the necessary data, Leadership behaviors scale and Job satisfaction scale. Results: The study results revealed moderate positive leadership behaviors scores and low job satisfaction by the studied educators. Conclusion: It can be concluded that highly statistical significant positive weak correlation existed between leadership behaviors and job satisfaction of the studied educators. Recommendations: it was recommended to improve leadership behaviors that inspire and motivate others, resolve conflicts in win-win way, and communicate effectively. Also, to increase educators job satisfaction it was recommended to communicate roles and responsibilities, maintain equity treatment, and demonstrating optimism \& positive energy.
\end{abstract}

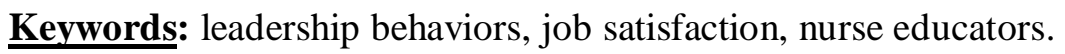

\section{Introduction}

Leadership and job satisfaction are organization. Nursing leaders seldom recognized as fundamental components influencing the overall effectiveness of an receive the proper leadership training necessary to lead an academic 
organization. As a result, the leader may burnout and his/her dissatisfaction may increase. Nursing educators can act as leaders by generating student motivation. Accordingly, nurse educators who have acquired the necessary leadership behaviors, and feel empowered to act, would then be able to mentor future nurse leaders $^{(1)}$.

In general, an organization's success depends on the effectiveness of leadership. Effective leadership requires both professional and personal leadership behaviors. Professional leadership behaviors include creating a mission and defining a process for reaching goals. Personal leadership behaviors include caring for and sharing with individuals and building trust. Also, effective leaders must be task and people oriented. Effective leaders understand the importance of defining and articulating a vision that embraces the diverse behaviors of employees and ensures that personal values work collaboratively with the values of the organization $^{(2,3)}$.

In addition, leadership is "the process of influencing others to understand and agree about what needs to be done and how to do it, and the process of facilitating individual and collective efforts to accomplish shared objectives". ${ }^{(4)}$ Four categories of effective leadership behaviors were described by Tsai (2011) as leader's encouragement and supportiveness to subordinates(LB1), leader giving subordinates a clear vision and trust(LB2), leader's behavior is consistent with organization's vision(LB3), and leader is persuasive in convincing subordinates to acknowledge the vision(LB4). Regarding "leader's encouragement and supportiveness to subordinates" the leader will: express high performance expectations for followers, communicate a high degree of confidence in the followers' ability to meet expectations, and support the decisions that people make on their own, talk about future trends that will influence how certain work gets done, and give followers appreciation and support for their contributions ${ }^{(5)}$.

Furthermore, according to "leader giving subordinates a clear vision and trust" the leader will: negotiates her/his ideas when it benefits her/his image or her/his vision, use positive rewards and reinforcement with her/his followers, and may change her/his vision to meet the needs and wants of the followers and the organization. Additionally, regarding "leader's behavior is consistent with organization's vision" the leader will: act accordingly to certain vision that specifies a better future state, strive toward distal rather than proximal goals, and 
communicate messages that contain references to her/his overall vision ${ }^{(5)}$.

Last but not least according to "leader is persuasive in convincing subordinates to acknowledge the vision" the leader will: excel in persuading people to agree with her/him, try to persuade those who disagree with her/his vision to agree with it, and delegate authority for the attainment of her/his vision $^{(5)}$.

Leaders have a significant influence on their employees' job satisfaction. Otherwise, leaders benefit from employees who are satisfied with their jobs more than employees who are dissatisfied. Satisfied employees result in lower turnover and higher productivity. Employee dissatisfaction increases the turnover rate and decreases productivity. Employee is often dissatisfied with pay, recognition, benefits, and appreciation ${ }^{(1)}$.

Effective leaders have the ability to exert influence and know how to involve others, enabling them to act within the correct vision, mission and goals of the organization. Leaders are also responsible for preparing followers to perform tasks. Accordingly, they must be flexible and willing to communicate with their followers $^{(6)}$.

An employee's job satisfaction is derived from the mental and physical satisfaction they experience in the work environment and from the work itself. Job satisfaction in general refers to the emotions the employee feels about his job, and how he reacts to them ${ }^{(7-10)}$. It is defined by Chen (2005) as an emotional state resulting from the evaluation of one's job that can be negative, neutral or positive. Job satisfaction dimensions that used in this study are: communication $\&$ teamwork (JS1), amount of time \& resources (JS2), management practices (JS3), and job recognition (JS4). Communication \& Teamwork include satisfaction about communication status between colleagues within their department and team work. Also, amount of time \& resources include amount of time and The pace or speed at which employee have to work and the supplies that used and the information get to do job. Furthermore, management practices include the way of management in department, pay and rewards benefits, and the amount of responsibility given to subordinate. Also, job recognition includes items as recognition of work, attention paid to suggestions, observations, and opinions $^{(11)}$.

Nurse educators fulfill many roles including that of teacher, supervisor, support person, and role model, and they are in a prime position to foster the development of a leadership mindset 
within nurses, act as talent scouts to seek out potential nurse leaders, encourage nurses to consider graduate education, and promote nursing leadership as a career track. $^{(12,13)}$ So, If nurse educators are expected to play a major role in the recruitment, development, and mentoring of future nurse leaders, they need to first develop their own leadership practices, and feel empowered to foster a leadership mindset within nurses ${ }^{(14)}$.

Salem (2011) conducted a study to describe the relationship between clinical educators perception of leadership behavior and compared with student perception of it. $\mathrm{He}$ stated that nurse educator effective leaderships are essential for the improvement of nursing education ${ }^{(15)}$. Also, Hosseini (2013) conducted study to analyze the relationship between transformational leadership and psychology empowerment of employees in the Islamic Azad Universities. He stated that effective leaders transfer respect and loyalty to the staff through their organizational interactions and reinforce a sense of responsibility. Moreover, those leaders though establishing a relationship with the staff, try to understand and respect the needs, skills and different aspiration. Also, leaders are trying to draw incentives perspective for employees toward future working group, and stimulate employees with the development of interests. More importantly, leaders carry a sense of competence with timely feedback ${ }^{(16)}$.

Leadership behavior is positively correlated with job satisfaction. Tsai (2011) discovered that within the research \& development and administrative environments, leadership behavior of a manager is closely related to work satisfaction of the employees ${ }^{(5)}$. Job satisfaction has been associated with employees who perceive their managers as supportive and caring. A supportive manager shares values, believes in a balance of power, and provides opportunities for open dialogue with employees, which in turn reduces the chances of internal conflicts. This type of leader is successful in his or her role and is supportive and responsive to employees. Such leaders are valued throughout the organization and have executive power to do what they see as necessary to create a positive environment for employees. Accordingly, they have a measurable effect on the morale and job satisfaction of employees. The quickest and most reliable way of increasing employee satisfaction and commitment is to provide employees with a more effective leader ${ }^{(17)}$.

Moreover, Positive leadership behaviors have a significant impact on the commitment and satisfaction of employees. 
leaders who stay in touch with issues and concerns of individuals in the work group have employees with higher levels of satisfaction and commitment. Furthermore, leaders who are effective at inspiring and motivating others have a high level of energy and enthusiasm. They energize their team to achieve difficult goals and increase the level of performance from everyone on the team. Additionally, leaders who provide their team with a definite sense of direction and purpose tend to have more satisfied and committed employees. Also, when leaders work with employees and push them to develop new skills and abilities, they are building higher levels of employee satisfaction and commitment. Employees who develop new skills become higher performers and more promotable ${ }^{(17)}$.

From the above mentioned, so positive leadership behavior is one of the most significant factors affecting the satisfaction of nursing educators. However, in Minia Faculty of Nursing limited studies have been conducted regarding nursing educators leadership and satisfaction. Therefore, the aim of this study was to assess relationship between leadership behavior and job satisfaction of nursing educators.

\section{Aim of the Study}

To examine the relationship between leadership behaviors and nurse educator's job satisfaction.

\section{Research Question:}

What is the relationship between leadership behaviors and nurse educator's satisfaction?

\section{Materials and Method}

\section{Materials}

Design: Descriptive - correlation design was used in this study.

Setting: This study was conducted at Faculty of Nursing, El-Minia University.

Subjects: The study subjects consisted of all nursing educators working in the previous setting and who were available at the time of data collection $(\mathrm{N}=80)$.

Tools: One tool was used for data collection. leadership behavior and job satisfaction questionnaire. This tool was developed by Solomon $(2009)^{(1)}$ and modified by Tsai (2011). ${ }^{(5)}$ It is consisted of two parts:

Part I: include leadership behavior scale consisted of 26 items subdivided to 4 subscales namely: leader's encouragement 
and supportiveness to subordinates (12 items), leader giving subordinates a clear vision and trust ( 7 items), leader's behavior is consistent with organization's vision (4 items), and leader is persuasive in convincing subordinates to acknowledge the vision (3 items). Likert scale was used for the participants responses, it ranged from strongly disagree (1) to strongly agree (5). A total score was calculated by summing up the scores of each item. A score range of 1-43 indicated low leadership behavior, a score range of 44-87 indicated moderate leadership behavior, and a score range of 88-130 indicated high leadership behavior with leadership behavior.

Part II: include Job satisfaction scale consisted of 12 items which subdivided to 4 subscales named communication \& teamwork (4 items), amount of time \& resources (2 items), management practices (3 items), and job recognition (3 items). Likert scale was used for the participants responses, it ranged from strongly dissatisfied (1) to strongly satisfied (5). A total score was calculated by summing up the scores of each item. A score range of 120 indicated low job satisfaction, a score range of 42-60 indicated moderate job satisfaction, and a score range of $28-40$ indicated high job satisfaction. Attached with personal data sheet including age, gender, department, and academic qualification.

\section{Method}

1- Permission to conduct the study was obtained from all responsible authorities (the dean and heads of nursing departments) of El-Minia Faculty of Nursing after explanation the purpose of the study.

2- Content validity of the questionnaire was done by 4 experts in the related fields namely nursing education (2 experts [faculty of nursingAlexandria University]) and nursing administration (2 experts [faculty of nursing- Cairo University]).

3- The reliability coefficient of the tool by Cronbach's alpha was 0.97 .

4- A pilot study was carried out on a sample of (10\%) from participants to check and ensure the clarity and applicability of the tools. Based on the findings corrections were done. The pilot subjects were not included in the main study subjects.

5- The questionnaire was individually administered to each 
participant in the study setting. 30 minutes was given to complete it. Data were collected from $1^{\text {st }}$ September to $30^{\text {th }}$ December 2012.

\section{Ethical considerations:}

Permission was obtained from all participants of the study after explanation of the study purpose and confidentiality of data was ensured.

\section{Statistical Analysis}

The data from the participants were entered and analyzed using statistical package for the social sciences software (SPSS) for windows (version 20). Data were presented using descriptive statistic in the form of frequency, percentage for qualitative variables and means and standard deviation for quantitative variables. Pearson correlation was calculated to evaluate the relationship between variables. $\mathrm{P}$ value of $\leq 0.05$ was used to assess the significance of the results.

\section{Results}

Table (1) illustrates the distribution of the studied nurse educators according to their general characteristics. It was noticed that the half of the studied educators
$(52.5 \%)$ were within the $23 \leq 30$ age range. Also, the majority of the study studied educators $(87.50 \%)$ were females. Moreover, nearly half of them (48.75\%) have master degree. Furthermore, the highest percent (20\%)of studied educators working in nursing administration department. In addition, half of the studied educators $(50 \%)$ had 5 to 10 years of experience.

Table (2) shows percent, mean, and standard deviation scores of leadership behaviors among the studied nurse educators. It was observed that the highest percent of moderate leadership behaviors were represented by Leader giving subordinate her/his clear vision and trust (LB2) and followed by Leader's encouragement and supportive to subordinates (LB1) ( $73.8 \%$ and $51.3 \%$ ) respectively. In Otherwise the same table shows that the highest percent of low leadership behaviors were represented by leader is persuasive in convincing subordinates to acknowledging her/his vision (LB4) and followed by leader's behavior is consistent with her/his vision (LB3) (75\% and 62.5\%) respectively.

Table (3) demonstrates percent, mean, and standard deviation scores of the studied nurse educators according to their job satisfaction. It was observed that the majority of the studied educators reported 
low job satisfaction. Additionally the highest percent of low job satisfaction were represented with management practices (JS3) followed by amount of time and resources (JS2) $\quad(97.5 \%, 93.75)$ respectively. On the other hand the same table shows that only $15 \%$ of the studied educators have moderate job satisfaction regarding communication and team work (JS1).

Table (4) presents the Pearson correlation between leadership behaviors and job satisfaction among the studied educators. It was noticed that there are highly statistical significant and positive weak correlation between total leadership behaviors and total job satisfaction of the studied educators. In addition, it was observed that there are highly statistical significant difference and positive weak correlation between total job satisfaction and both leadership behaviors named leader giving subordinate her/his clear vision and trust (LB2) and leader is persuasive in convincing subordinates to acknowledging her/his vision (LB4) $(\mathrm{P}=$ 0.004, $\mathrm{r}=0.315$ and $\mathrm{P}=0.007, \mathrm{r}=0.299$ ) respectively. Also, the same table shows statistical significant difference and positive weak correlation between total job satisfaction and leadership behavior named leader's encouragement and supportive to subordinates $(\mathrm{LB} 1)(\mathrm{P}=0.011, \mathrm{r}=0.284)$.
On the other hand, the same table indicates no correlation and no statistical significant difference were found between JS2, JS3, and LB1 $(\mathrm{P}=0.464, \mathrm{r}=0.083$ and $\mathrm{P}=0.076, \mathrm{r}=0.200)$ respectively. Additionally, no correlation and no statistical significant difference were found between JS4 and LB4 $(\mathrm{P}=0.174, \mathrm{r}=$ 0.154). Moreover, this table shows no correlation and no statistical significant difference between total job satisfaction and LB3 $(\mathrm{P}=0.071, \mathrm{r}=0.203)$.

\section{Discussion}

Job satisfaction is individuals' attitudes and feelings towards their jobs. In a way that positive feelings and attitudes about job reflects satisfaction and negative feelings and attitudes about it reflects a lack of job satisfaction ${ }^{(18)}$. The study of job satisfaction is a topic of wide interest to both people who work in organizations and people who study them. Job satisfaction is complex phenomenon with multi facet, it is influenced by the factors like salary, working environment, autonomy, communication, and organizational commitment. Also, Job satisfaction has been closely related with many organizational phenomena such as motivation, performance, leadership, attitude, conflict, and moral. In order to make employees satisfied and committed 
to their jobs in academic and research organizations, there is need for strong and effective motivation at the various levels, departments, and sections of the organization $^{(19)}$.

The finding of present study revealed that the studied educators reported moderate leadership behaviors scores. This finding supported our expectations after the 25th January revolution. It was set to establish a new social contract, based on social justice, respect of all social segment rights, and democracy. Lack of good governance lead to mass protests. Also it inspired university students expressed their demands in peaceful, as well as aggressive demonstrations, and actions. The level of security in general and the efficiency of the security system have decreased in urban as well as rural areas. Moreover, lack of security measures in Egyptians' universities $^{(20)}$.

Also, in my opinion I think that since January 25th 2011 until the date of data collection of the present study on September $1^{\text {st }}, 2012$ no actual reforms in politics, economy, or in any other social field happened, corruption in all organizations still exists. So, these social exchanges lead to poor relationships, inadequate recognition systems, overwork, low pay, and lack of respect between nursing educators leaders, nursing educators, and students. Additionally, from my viewpoint factors that contributed to reporting moderate leadership behaviors by the studied nursing educators may include a perceived lack of control over decision making coupled with too much responsibility, a perceived lack of support from managers leading to increased work stress, a feeling of an inability to please everybody, and a fear of failure leading to feeling less job security.

On the other hand, this finding contradict with the study conducted by Lummus (2010) who found that leadership behavior was ranked as highest percent ${ }^{(21)}$. Also, he reported that highest rating of importance leadership behavior was given to "sets a personal example of what expected of others". Moreover, Gallagher (2010) stated that leadership based on building relationships and motivating staff members through a shared vision and mission. Effective leaders typically have charisma to communicate vision, confidence to act in a way that inspires others, staff respect and loyalty from letting the team know they are important, and are masters at helping people do things they weren't sure they could do by giving encouragement and praise ${ }^{(22)}$.

Moreover, the results of the present study revealed that the highest percent of moderate leadership behaviors reported by 
the studied educators with" Leader giving subordinate her/his clear vision and trust" (LB2). Sample items include make sure that people are creatively rewarded for their contributions to the success of projects and actively listen to diverse points of view. This result in agreement with Tsai (2011) who stated that leader behaviors includes advance planning, goal clarification, and task focus, as well as with effects such as value congruence ${ }^{(5)}$. Also, this finding in the same line with Reave (2005) who reported that rewarding (praise) was one of four consistent differentiators between good and bad leadership ${ }^{(23)}$.

Furthermore, the finding of this study indicated that the second highest percent of moderate leadership behaviors reported by the studied educators with 'Leader's encouragement and supportive to subordinates" (LB1). Sample items include challenge subordinates to try out new innovative ways to do their work, praise people for a job well done, set a personal example of what expected of others, and develop cooperative relationships among the people in their work. This finding is in accordance with the results of the Thompson et al. (2005) who reported that the role of leaders was to establish a work environment that increased the values and interdependence of $\operatorname{staff}^{(24)}$. Moreover,
Love (2005) concluded, the best leaders are aware of the emotional and intellectual intelligence necessary to empower people to take action, to solve problems, and to voice their ideas. Leaders are expected to develop trust and self-confidence in the team $^{(25)}$. Additionally, This finding agrees with Solomon (2009) who stated that leaders should stimulate interest among their followers for new perspectives, develop them to reach higher levels of their potential, generate awareness among them for the mission and vision of the group, and motivate them to look beyond their own interests and consider the good of their group. Also, encourage their employees to reach higher performance standards and they initiate growth and change in the organization $^{(1)}$.

In addition, the results of present study revealed low job satisfaction of the studied educators. This finding contradicts with Mullally (2013) who stated that Nurse educators often express a high degree of satisfaction with their work. They typically cite interaction with students and watching future nurses grow in confidence and skill as the most rewarding aspects of their jobs. Mentoring students and watching them gain confidence and skills are particularly rewarding aspects of their jobs. Other benefits include access to cutting-edge knowledge and research, opportunities to 
collaborate with health professionals, an intellectually stimulating workplace, and a flexible work environment ${ }^{(18)}$.

Furthermore, the results of the present study demonstrated that the highest percent of low job satisfaction reported by the studied educators with "Management practices" (JS3). Sample items include the way of management in department, pay and rewards benefits, and the amount of responsibility given to subordinate. These findings in contrast with Chamber (2010) who stated that supervisors that are employee centered, listen to feedback, praise good performance, and collaborate tend to receive higher satisfaction ratings. He also mentioned that factors that caused satisfaction emerged in the work itself: achievement, recognition, responsibility and advancement ${ }^{(26)}$.

Also, the finding of this study demonstrated that the second highest percent of low job satisfaction reported by the studied educators with "Amount of time \& Resources (JS2). Sample item include amount of time and the pace or speed at which employee have to work and the supplies that used and the information get to do job. This finding supported by Ketefian (2001) who stated that several factors may contribute to level of job satisfaction: organization culture; communication with leaders and colleagues; equipment and facilities. Additionally, when leaders practice management skills and use resources effectively, they increase the quality care for delivery services, motivate staff, and improve the welfare of employee to perform their duties more effectively ${ }^{(27)}$.

Last but not least, the results of the present study revealed that highly statistical significant positive weak correlation existed between total leadership behaviors and total job satisfaction of the studied educators. This finding is in accordance with Solomon (2009) who stated that interaction with leaders can have a positive impact on employee satisfaction. When employees experience constant support from managers, they are more likely to be satisfied and perform effectively within the organization ${ }^{(1)}$. Also, Perkins (2010) stated that leadership has been accepted as the key factor of a worker's job satisfaction and organizational effectiveness $^{(28)}$.

Finally, Reave (2005) suggested that treating others with respect and fairness, expressing caring and concern, listening responsively, appreciating others, and taking time for personal reflection have all been linked to quantifiable positive effects for organizations and individuals. They cause leaders to be judged as more effective by both their peers and their 
subordinates, and they lead to enhanced performance. They have been proven to be associated with increased worker satisfaction and motivation, greater productivity, greater sustainability ${ }^{(23,29)}$.

In particular, leadership impacts on teamwork, teamwork impacts on structure, structure influences burnout, and burnout influences attitudes towards job ${ }^{(30)}$.

\section{Conclusion}

- Moderate leadership behaviors scores reported by the majority of studied nurse educators.

- Low job satisfaction reported by the studied educators.

- Highly statistical significant relation and positive weak correlation was found between leadership behaviors and job satisfaction of the studied educators.

\section{Recommendations}

In the light of the findings of this study, the following are recommendations:
- Nursing education program should integrate leadership theory and practice across curriculum.

- Nurse educators should seek opportunities to develop and to exercise their leadership skills through attending training programs about leadership, managerial skills.

- Sharing in decision making related to teaching-learning process or management of the college.

- Facilitate team problem solving

- Maintain equity treatment of nurse educators

- Create a workplace culture that values real people relationships.

- Solve problems and provide resources that are needed to facilitate achievement of the work.

\section{Recommendations for future studies:}

- Greater sample size and various study settings recommended for further studies.

- Conduct a study to assess the differences and relationship between the level of nursing educators' job satisfaction, motivation and their teaching performance. 
Table (1): Frequent distribution of the studied nurse educators according to their general characteristics.

\begin{tabular}{|c|c|c|}
\hline General Characteristic & No $(80)$ & $\%$ \\
\hline \multicolumn{3}{|l|}{ 1- Age(years): } \\
\hline $23>30$ & 42 & 52.5 \\
\hline $30>40$ & 32 & 40 \\
\hline $40<$ & 6 & 7.5 \\
\hline $\mathrm{X} \pm$ S.D & \multicolumn{2}{|c|}{$30.69 \pm 5.50$} \\
\hline \multicolumn{3}{|l|}{ 2- Gender: } \\
\hline Male & 10 & 12.50 \\
\hline Female & 70 & 87.50 \\
\hline \multicolumn{3}{|l|}{ 3-Academic qualification } \\
\hline - Baccalaureate degree & 24 & 30.00 \\
\hline - Master degree & 39 & 48.75 \\
\hline - Doctorate degree & 13 & 16.25 \\
\hline - Post doctorate degree & 4 & 5.00 \\
\hline \multicolumn{3}{|l|}{ 4- Nursing Department } \\
\hline - Medical surgical & 15 & 18.75 \\
\hline - Geriatric & 3 & 3.75 \\
\hline - Pediatric & 12 & 15.00 \\
\hline - Psychiatric & 13 & 16.25 \\
\hline - Administration & 16 & 20.00 \\
\hline - Obstetric & 15 & 18.75 \\
\hline - Community health & 6 & 10.00 \\
\hline \multicolumn{3}{|l|}{ 5- years of experience } \\
\hline Less than 5 years & 27 & 33.8 \\
\hline From 5-10 years & 40 & 50 \\
\hline More than 10 years & 13 & 16.3 \\
\hline
\end{tabular}


Table (2): Percent, Mean, and Standard deviation scores of leadership behaviors among the studied nurse educators. $\mathbf{n}=\mathbf{8 0}$.

\begin{tabular}{|c|c|c|c|c|c|c|c|c|}
\hline \multirow{3}{*}{ Score } & \multicolumn{8}{|c|}{ Leadership Behaviors } \\
\hline & \multicolumn{2}{|c|}{$\begin{array}{c}\text { Leader's } \\
\text { encouragement } \\
\text { and supportive to } \\
\text { subordinates } \\
\text { ( LB1) }\end{array}$} & \multicolumn{2}{|c|}{$\begin{array}{l}\text { Leader giving } \\
\text { subordinate } \\
\text { her/his clear } \\
\text { vision and trust } \\
\text { (LB2) }\end{array}$} & \multicolumn{2}{|c|}{$\begin{array}{l}\text { Leader's behavior } \\
\text { is consistent with } \\
\text { her/his vision } \\
\text { (LB3) }\end{array}$} & \multicolumn{2}{|c|}{$\begin{array}{c}\text { Leader is } \\
\text { persuasive in } \\
\text { convincing } \\
\text { subordinates to } \\
\text { acknowledging } \\
\text { her/his vision } \\
\text { (LB4) }\end{array}$} \\
\hline & No & $\%$ & No & $\%$ & No & $\%$ & No & $\%$ \\
\hline Low (1-43) & 0 & 0 & 21 & 26.3 & 30 & 62.5 & 60 & 75 \\
\hline Moderate (44-87) & 41 & 51.3 & 59 & 73.8 & 50 & 28.5 & 20 & 25 \\
\hline High (88-130) & 39 & 48.8 & 0 & 0 & 0 & 0 & 0 & 0 \\
\hline Mean \pm SD & \multicolumn{2}{|c|}{$40.58 \pm 5.454$} & \multicolumn{2}{|c|}{$22.112 \pm 4.009$} & \multicolumn{2}{|c|}{$44.875 \pm 6.508$} & \multicolumn{2}{|c|}{$35.562 \pm 7.914$} \\
\hline
\end{tabular}

Table (3): Percent, Mean, and standard deviation scores of the studied nurse educators according to their job satisfaction. $\mathbf{n = 8 0}$.

\begin{tabular}{|c|c|c|c|c|c|c|c|c|}
\hline \multirow{3}{*}{ Score } & \multicolumn{8}{|c|}{ Job Satisfaction } \\
\hline & \multicolumn{2}{|c|}{$\begin{array}{c}\text { Communication } \\
\text { \& Teamwork } \\
\text { (JS1) }\end{array}$} & \multicolumn{2}{|c|}{$\begin{array}{l}\text { Amount of time } \\
\text { \& Resources } \\
\text { (JS2) }\end{array}$} & \multicolumn{2}{|c|}{$\begin{array}{c}\text { Management } \\
\text { practices } \\
(\mathrm{JS} 3)\end{array}$} & \multicolumn{2}{|c|}{$\begin{array}{l}\text { Job recognition } \\
\text { (JS4) }\end{array}$} \\
\hline & No & $\%$ & No & $\%$ & No & $\%$ & No & $\%$ \\
\hline Low (1-20) & 68 & 85 & 75 & 93.75 & 78 & 97.5 & 72 & 90 \\
\hline Moderate (21-41) & 12 & 15 & 5 & 6.25 & 2 & 2.5 & 8 & 10 \\
\hline High (42-60) & 0 & 0 & 0 & 0 & 0 & 0 & 0 & 0 \\
\hline Mean \pm SD & \multicolumn{2}{|c|}{$17.563 \pm 3.396$} & \multicolumn{2}{|c|}{$11.838 \pm 2.717$} & \multicolumn{2}{|c|}{$10.563 \pm 2.049$} & \multicolumn{2}{|c|}{$9.725 \pm 2.061$} \\
\hline
\end{tabular}


Table (4): Pearson Correlation between leadership behaviors and job satisfaction among the studied nurse educators $=\mathbf{8 0}$.

\begin{tabular}{|c|c|c|c|c|c|c|c|c|c|c|}
\hline \multirow{3}{*}{$\begin{array}{c}\text { Leadership } \\
\text { Behavior }\end{array}$} & \multicolumn{10}{|c|}{ Job Satisfaction } \\
\hline & \multicolumn{2}{|c|}{$\begin{array}{l}\text { Communicati } \\
\text { on \& } \\
\text { Teamwork } \\
\text { (JS1) }\end{array}$} & \multicolumn{2}{|c|}{$\begin{array}{l}\text { Amount of } \\
\text { time \& } \\
\text { Resources } \\
\text { (JS2) }\end{array}$} & \multicolumn{2}{|c|}{$\begin{array}{c}\text { Management } \\
\text { practices } \\
(\mathrm{JS} 3)\end{array}$} & \multicolumn{2}{|c|}{$\begin{array}{c}\text { Job } \\
\text { recognition } \\
(\text { JS4) }\end{array}$} & \multicolumn{2}{|c|}{ Total } \\
\hline & $\begin{array}{c}\mathrm{r} \\
\text { value } \\
\end{array}$ & $\begin{array}{c}\mathrm{P} \\
\text { value } \\
\end{array}$ & $\begin{array}{c}\mathrm{r} \\
\text { value } \\
\end{array}$ & $\begin{array}{c}\mathrm{P} \\
\text { value } \\
\end{array}$ & $\begin{array}{c}\mathrm{r} \\
\text { value }\end{array}$ & $\begin{array}{c}\mathrm{P} \\
\text { value } \\
\end{array}$ & $\begin{array}{c}\mathrm{r} \\
\text { value } \\
\end{array}$ & $\begin{array}{c}\mathrm{P} \\
\text { value } \\
\end{array}$ & $\begin{array}{c}\mathrm{r} \\
\text { value }\end{array}$ & $\begin{array}{c}\mathrm{P} \\
\text { value }\end{array}$ \\
\hline $\begin{array}{c}\text { Leader's } \\
\text { encouragement and } \\
\text { supportive to } \\
\text { subordinates ( LB1) }\end{array}$ & $0.267 *$ & 0.02 & 0.083 & 0.464 & 0.200 & 0.076 & $\begin{array}{c}0.341^{*} \\
*\end{array}$ & 0.002 & $0.284 *$ & 0.011 \\
\hline $\begin{array}{c}\text { Leader giving } \\
\text { subordinate her/his } \\
\text { clear vision and } \\
\text { trust (LB2) }\end{array}$ & $0.263^{*}$ & 0.018 & $0.255^{*}$ & 0.023 & $0.228 *$ & 0.042 & $0.274 *$ & 0.014 & $\begin{array}{c}0.315^{*} \\
*\end{array}$ & 0.004 \\
\hline $\begin{array}{l}\text { Leader's behavior is } \\
\text { consistent with } \\
\text { her/his vision (LB3) }\end{array}$ & $0.248 *$ & 0.027 & 0.133 & 0.238 & 0.103 & 0.365 & 0.155 & 0.170 & 0.203 & 0.071 \\
\hline $\begin{array}{l}\text { Leader is persuasive } \\
\text { in convincing } \\
\text { subordinates to } \\
\text { acknowledging } \\
\text { her/his vision (LB4) }\end{array}$ & $0.258 *$ & 0.021 & $\begin{array}{l}0.294 * \\
*\end{array}$ & 0.008 & $0.270 *$ & 0.015 & 0.154 & 0.174 & $\begin{array}{c}0.299 * \\
*\end{array}$ & 0.007 \\
\hline Total & $\begin{array}{c}0.330^{*} \\
*\end{array}$ & 0.003 & $0.216^{*}$ & 0.050 & $0.253 *$ & 0.024 & $\begin{array}{c}0.331 * \\
*\end{array}$ & 0.003 & $\begin{array}{c}0.355^{*} \\
*\end{array}$ & 0.001 \\
\hline
\end{tabular}

** Correlation is significant at the 0.001 level. *Correlation is significant at the 0.05 level. 


\section{References}

1. Solomon J. Influence of leadership on nursing assistants' job satisfaction in a central Maryland nursing home. Unpublished doctoral theses. School of Advanced study, University of Phoenix, 2009.

2. Worden S. The role of integrity as mediator in strategic leadership: A recipe for reputational capital. Journal of Business Ethics, 2003; 46(1): 31.

3. Yukl G. Leadership in organizations. $6^{\text {th }}$ ed. Upper Saddle River, NJ: Pearson Prentice Hall; 2006.pp.8.

4. Yukl G, Gordon A, Taber T. A hierarchical taxonomy of leadership behavior: Integrating a half century of behavior research. Journal of Leadership \& Organizational Studies, 2002; 19(1):15-32.

5. Tsai Y. Relationship between organizational culture, leadership behavior and job satisfaction. Services Research Journal, 2011; 11(1): 88-98.

6. Sternke J. A case study of the leadership traits and behaviors of school superintendents in exemplary school districts. Doctoral theses, college of Education and Leadership, Cardinal Stritch University; 2011.
7. Tsui S, Zhang $X$, Katherine $\mathrm{R}$. Unpacking the relationship between CEO leadership behavior and organizational culture. Leadership Quarterly, 2006; 17(1):113-137.

8. Laschinger K, Judith S, Donna T. Impact of magnet hospital characteristics on nurses' perceptions of trust, burnout, quality of care, and work satisfaction. Nursing Economic, 2001; 19(5):209-219.

9. Elizabeth J, Ann E. The changing nature of nurses' job satisfaction. Journal of Advanced Nursing, 1999; 30(1):150 158.

10. Gifford D, Raymond F, Goodman A. The relationship between hospital unit culture and nurses' quality of work life. Journal of Healthcare Management, 2002; 47(1):13-25.

11. Chen T. Exploring the relationship among transformational and transactional leadership behavior, job satisfaction, organizational commitment, and turnover on the it department of research and development in shanghai, China. Doctoral theses, School of Computer and Information Sciences. Nova South western University. 2005.

12. Stutsky B. Empowerment and leadership development in an online story-based learning community. Doctoral theses. 
Graduate School of Computer and Information Sciences. Nova Southeastern University. 2009.

\section{Conway J, Elwin C. Mistaken,} misshapen and mythical images of nurse education: Creating a shared identity for clinical nurse educator practice. Nurse Education in Practice, 2007; 7(3): 187 194.

14. Sherman O, Bishop M. The role of nurse educators in grooming future nurse leaders. Journal of Nursing Education, 2007; 46(7): 295-296.

15. Salem O, Baddar F, Putri G. Leadership behavior as perceived by clinical teacher and nursing students. Life Science Journal, 2011; 8(4): 814-820.

16. Hosseini S, Khalatbari J. Relationship between transformational leadership styles with psychological empowerment. Life Science Journal 2013; 10(1):461469.

17. Mehdi R, Zahra P, Mahshid N. Job satisfaction and organizational commitment among nurses. Life Science Journal, 2013; 10(5):1-5.

18. Bakhshayesh H, Vahdat R, Sheikhzadeh M. Examine the relationship between job satisfaction and organizational commitment of teachers to the academic success of elementary students in Heris.
Life Science Journal, 2013; 10(3) 171176.

19. Parvin M. Factors affecting employee job satisfaction of pharmaceutical sector. Australian journal of business and management research, 2011; 1(9):113123.

20. El-Tantawy N. Social media in the Egyptian revolution. International Journal of Communication, 2011; 5(1):1207-1224.

21. Lummus S. Perceptions of required leadership behaviors for nurse leaders as measured by the leadership practices inventory. Doctoral Theses. Graduate School of Education and Psychology. Pepperdine University.2010.

22. Gallagher A, Verena T. Educating for ethical leadership. Nurse Education Today, 2010; 30(1) 224-227.

23. Reave L. Spiritual values and practices related to leadership effectiveness. The Leadership Quarterly Journal, 2005; 16 (1): 655-687.

24. Thompson A, Navarra B, Antonson N. Patient safety: The four domains of nursing leadership. Nursing Economics, 2005; 23(1): $331-334$

25. Love T. Using both head and heart for effective leadership. Journal of Family 
and Consumer Science, 2005; 97(2):1720.

26. Chamber S. Job satisfaction among elementary school teachers. Doctoral theses, school of education. University of North Carolina, 2010.

27. Ketefian, S. The development of advanced practice roles: Implications in the international nursing community. Internal Nurse Review, 2001; 48(1):152-163.

28. Perkins L. Nurse managers transform nursing: A study of leadership behaviors and the relationship to leadership training and employee satisfaction, doctoral theses, School of Education, Capella University, 2010.
29. Schindler K. An analysis of the relationship of perceived principal instructional leadership behaviors and student academic achievement. Doctoral theses. College of Graduate Studies, Tarleton State University, 2012.

30. Ahmed S, Elsayed L, El-Nagger N. Effect of motivation versus demotivation on job satisfaction among the nurses working in hera general hospital at makkah al-mukramh. Life Science Journal, 2013; 10(2):450-457. 